and was unrelated to 'notions' about the Earth. Projected maps, based in theory on astronomical fixes, began to be drawn in the late fifteenth and early sixteenth centuries. All maps are 'plane' in Cortes' sense, i.e. they are drawn on a flat, instead of a globular surface. They are therefore all imperfect, and the fact that maritime charts failed to show the convergence of the meridians was constantly stressed. Mercator's is a 'plane chart'. But it does not give 'a true representation of the Earth on a plane surface' as Lieutenant-Commander Waters states. It grossly distorts the shape of the continents, yet provided one has a table of meridional parts, it can give correct information about direction and distance. The term 'plane' was used in its correct geometrical sense by diallists, but Eden had no mathematics and writes 'playne'. The ambiguity of 'plaine or ordinary' I sufficiently demonstrated, but my 'as though' they were synonymous was printed as 'although'.

\title{
The Plane Sailings
}

\section{from C. H. Cotter}

IF a 'sailing' is defined as a means of finding by calculation, tables or construction, either: (a) the course and distance from one place to another, or $(b)$ the position of arrival after making a given course and distance from a given position, then what is commonly known as 'plane sailing' is not in this sense, a sailing at all. 'Plane' or 'Plain' sailing according to modern as well as early usage involves the arguments, distance, $d$. lat., departuse and course angle, and in order to solve the problems $(a)$ or $(b), d$. long., and either meridional $d$. lat. or 'middle' (not 'mean') latitude must enter the solution.

When a ship sails along any rhumb line except a meridian or parallel of latitude, the distance sailed, the $d$. lat. between the initial and final positions, and the departure between the initial and final positions, may be regarded as the sides of a plane right-angled triangle, the angle opposite the side representing departure being equal to the course angle. This plane triangle is essentially an artifice which shows the trigonometrical relationships between the arguments involved. These relationships are now known as the plane sailing formulae, namely:

$$
\begin{aligned}
\text { departure } & =\text { distance } \times \text { sine course } \\
d . \text { lat. } & =\text { distance } \times \text { cosine course } .
\end{aligned}
$$

Now it is a common belief amongst navigators that this artifice represents a triangle on the Earth's surface. This belief is strengthened by such definitions as'plane sailing is the art of navigating a ship on the supposition that the Earth is an extended plane'. Because the Earth is spherical no triangular area on its surface, however small, can be a plane triangle, but the somewhat false argument put forward is that the smaller is a triangle on the Earth, the more nearly is it plane. The question then arises as to what is the limiting distance sailed for assuming such a triangle to be plane? The distance that springs to the minds of many navigators is 600 miles-presumably because the traverse table extends to this figure in the distance column. A certain confusion arises when the distance involved exceeds 600 miles. 
Plane sailing does not imply, as Captain Topley suggests (this Journal, 8, 367), that only a small part of the Earth's surface is involved: the canons of plane sailing hold good regardless of the value of the distance.

The term 'plain sailing' as used at present to refer to something that presents little or no difficulty, possibly results from the ease with which the early navigators were able to solve plain and mercator sailing, in which cases the doctrines of plane trigonometry were used, compared with the difficulty of performing what John Davis described as 'the chiefest of all', namely greatcircle sailing, in which spherical trigonometry was used. The term plane sailing could at present be applied to parallel, mercator or middle-latitude sailing, as in every one of these cases, plane and not spherical trigonometry is used.

The confusion referred to above, is in many cases due to the fact that the average or 'mean' latitude of two places on a spherical Earth, may be used for converting departure into $d$. long. without introducing material error, only if the rhumb line distance between the two places is not too great and the mean latitude not too high.

Parallel sailing involves the problem of converting departure into $d$. long., or vice versa, when a ship sails along a parallel. In this case the ratio departure : $d$. long. for a spherical Earth, is equal to the cosine of the latitude of the parallel. When, however, a ship sails obliquely across meridians, the angle whose cosine is the ratio departure: $d$. long. is not the mean latitude. It is an angle which was known as the 'true middle latitude', but which is now referred to as simply 'middle' latitude, a term not by any means a suitable one, owing to its similarity with the term 'mean' latitude.

The term 'mean latitude sailing' applies to problems which are referred to in the Admiralty Navigation Manual as 'short-distance sailing' problems. It is stated that the mean latitude instead of the middle latitude may be used for solving sailing problems if the distance involved is less than 600 miles. For accurate results - and surely we should not, when possible, be content with results that are not accurate-the mean latitude is often not good enough even for some practical problems, and what has become known as 'middle-latitude sailing' must be used.

A further confusion arises in connection with mercator and middle-latitude sailings. A surprising number of navigators fail to realize that a rhumb line sailing problem may be solved accurately by either method. Many believe that middle-latitude sailing should not be used when distances greater than 600 miles are involved-the magic figure 600 is again quoted, presumably because of the traverse table again.

After Workman in 1805 introduced his table of corrections for converting mean into middle latitude, his method of solving the rhumb line sailing problem became in effect, 'mercator sailing by Mr. Workman's method', as opposed to the alternative of using a table of meridional parts, which method is of course 'mercator sailing by Mr. Wright's method'. I am sure that many present-day navigators never associate Workman's table (or its successor) with the meridional parts table.

As Mr. Tyrrell suggests (this Journal, 8, 366), needless .confusion amongst students could be avoided if some standardization in connection with sailings could be adopted. For practical navigation, the sailings which involve the use of plane trigonometry may be referred to collectively as 'rhumb-line sailings'. These may be classified as: 
1. Plane sailing

2. Middle-latitude sailing.

3. Mercator sailing.

The term plane sailing here means the relationship between rhumb line distance, $d$. lat., departure, and course angle. Middle-latitude sailing means the relationship between departure, $d$. long. and latitude. Mercator sailing means the relationship between $d$. long., meridional $d$. lat. and course angle.

Parallel sailing and meridian sailing are omitted, as they are simply special cases of middle-latitude sailing. When converting departure into d. long., or vice versa, the middle latitude should always be used. Even if the correction to apply to the mean latitude to obtain the middle latitude is small enough to be ignored, the name given to the angle used for the conversion should be 'middle' latitude. For this reason, 'mean-latitude sailing' does not appear in my classification.

Students should note that in order to solve either of the general sailing problems as defined in the opening paragraph, a combination of either plane and mercator, or plane and middle-latitude sailings must always be used.

[Mr. Sadler's paper Spheroidal Sailing and the Middle Latitude, printed on p. 371, deals with some of the same problems as Captain Cotter's, though both were of course conceived and written quite independently. $-E d$.

\section{Champlain's English Log from D. Chilton}

IN Lieutenant-Commander Waters' paper 'The Development of the English and the Dutchman's Log' (this Journal, 9, 70) there is an illustration (Fig. I, p. 73) of the English log, reproduced from Champlain's Les Voyages de la Nouvelle France Occidentale. The device illustrated, though no doubt correct in intention, could not have performed the function stated, namely, of floating 'vertically in the water presenting its full face to the ship's wake' (p. 74). This raises the

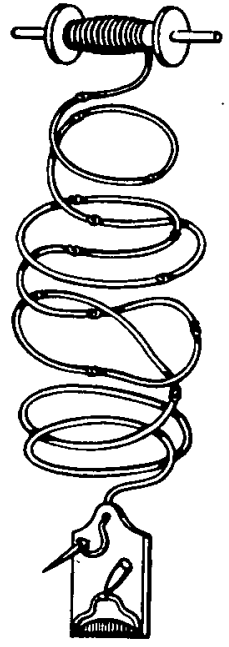

(o)

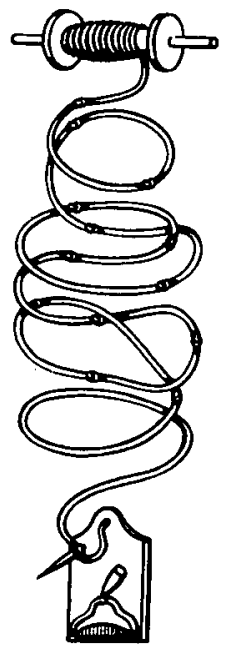

(b) suspicion that Champlain had not examined the log minutely enough, if at all, or at least had failed to instruct his draughtsman properly.

A simple modification of the illustration would correct it, and the original and a suggested modification are reproduced herewith. In the modification (b) the stray-line ends at the hole in the log-chip and the pin is attached at a suitable distance from the end. When the pin is plugged firmly into the socket the "crow foot' is formed and, if the line runs freely, the log-chip will then float vertically resisting 'any tendency of the log-line to draw it home to the ship' (loc. cit.). With this arrangement, if the stray-line is pulled taut, the pin will be jerked out of its socket and the log may easily be hauled-in. 